\title{
O capitalismo no início do século XXI: consumo e desfrute como imperativos morais
} SCRIBANO, Adrián. Dísfrutalo! Una aproximación a la Economía Política de la Moral desde el consumo. Buenos Aires: Elaleph.com, 2015.

\section{Resumo}

Nesta resenha, os autores apresentam e discutem um dos livros mais recentes de Adrián Scribano, que descrevem como uma obra complexa, densa, criativa e crítica. Um esforço para retratar o capitalismo, no Sul Global, no início do século XXI, como um imperativo moral, a obra reflete anos de reflexão teórica e pesquisa empírica e perpassa diversos temas das sociedades capitalistas contemporâneas.

Palavras-chave: Adrián Scribano. Consumo mimético. Religião neocolonial. Solidarismo.

\section{Capitalism at the beginning of 21st Century:} consumption and enjoyment as moral imperatives

\section{Abstract}

In this review, the authors present and discuss one of the more recent books by Adrián Scribano, describing it as a complex, dense, creative and critical work. An effort to depict capitalism, in the Global South, at the beginning of $21^{\text {st }}$ Century, as a moral imperative, the book reveals years of theoretical reflection and empirical research and spans many themes of contemporary capitalist societies.

Keywords: Adrián Scribano. Mimetic consumption. Neocolonial religion. Solidarism.

\footnotetext{
* Universidade Federal de Pelotas (Brasil)
} 
Depois de ler o livro, "Dísfrutalo! Una aproximación a la Economia Política de la Moral desde el consumo", poderíamos fazer-nos a mais simples das perguntas: de que ele trata? Do consumo? Da moral no capitalismo contemporâneo? Do desfrute? De como se integram as sociedades contemporâneas, no sentido classicamente durkheimiano? Da expansão do mercado como força hegemônica no capitalismo neocolonial? A riqueza da obra que nos propõe Adrián Scribano reside em que diversos temas das sociedades capitalistas contemporâneas podem ser observados a partir dele. Na leitura que fizemos da obra, entendemos que o livro é uma tentativa de desenhar o formato que adquire o capitalismo, principalmente como imperativo moral, no início do século XXI, no "Sul Global". Ao mesmo tempo, o livro pode ser visto também como um programa de pesquisa que nos lança em diversas direções, antes que uma obra fechada sobre um tema único.

A boa notícia que trazemos para o leitor, ao nos depararmos com este livro, é que se trata de uma obra complexa, densa, criativa e crítica. Fica evidenciado, ao longo de suas páginas, que é o resultado de anos de pesquisa teórica e empírica. Trata-se de um texto teoricamente denso, apoiado em boa medida na tradição marxista e, especialmente na teoria crítica, isto é, nos grandes clássicos da Escola de Frankfurt, com papel de destaque para Adorno e Horkheimer. Delas, extrai tanto a preocupação teórica por descortinar quais são os mecanismos e os dispositivos que explicam as engrenagens do capitalismo contemporâneo, como a de enxergar, na multiplicidade do social, em que lugares podem ser detectadas práticas disruptivas com o sistema dominante. Isso não significa, ainda, que Scribano não dialogue com os autores mais contemporâneos. Assim, nomes como os de Bourdieu, Giddens, Baudrillard, entre outros, contribuem para construir este rico arcabouço conceitual. 
Apoiar-se nessas tradições - de "gigantes" - e em uma leitura atual e criativa do capitalismo, conduz a uma riqueza conceitual instigante e sedutora para compreender o mundo hoje. Também é importante ressaltar quais têm sido, efetivamente, as preocupações de Scribano ao longo de sua obra, da qual o livro que apresentamos aqui pode ser visto como uma nova síntese. Nesse sentido, no seu percurso intelectual, temos os estudos da teoria crítica, os da ação coletiva e do conflito social, os da sociologia do corpo e das emoções e os da crítica ideológica.

A notícia não tão boa é que a leitura requer uma imersão em conceitos que nem sempre são explicitados. Conceitos teoricamente densos muitas vezes nos levam a outras cadeias de conceitos que precisam ser explicados, como é o caso das tríades conceituais que aparecem de forma abundante ao longo do texto. $\mathrm{O}$ autor percebe, às vezes, a necessidade de explicitação de conceitos que são fruto de um trabalho de elaboração construído através de seu périplo intelectual. Nessas ocasiões, a explicação conceitual mostra toda sua riqueza. Em outras, passa de forma talvez demasiado rápida pelos conceitos e "ficamos a ver navios". Ali, se faz necessário mergulhar não apenas nesta obra, mas também em outros textos que são referenciados no decorrer do livro. Só desse modo conseguimos compreender, em toda a sua complexidade, não apenas esta obra, mas sim o pensamento inovador que nela está presente. Em outras palavras, temos um autor exigente que precisa de leitores também exigentes.

Uma dificuldade adicional é que os casos empíricos têm uma baixa presença ao longo da obra, com a exceção do capítulo terceiro, dedicado às práticas estatais desde os chamados governos "progressistas", na América Latina, dos últimos quinze anos. No entanto, as múltiplas referências a outras obras - do autor e dele com colaboradores - abrem a possibilidade de observar mais em detalhe os casos empíricos que fundamentam os percursos teóricos. O leitor precisará também dessa imersão para perce- 
ber que os conceitos teóricos descrevem realidades empíricas observadas e analisadas pelo autor, não se reduzindo então o texto em questão a ser, apenas, uma obra de reflexão teórica.

Scribano vem construindo uma textura sociológica - às vezes em colaboração, às vezes, sozinho - desde as últimas décadas do século XX. É um pensamento original, frutífero, que, aliás, abre caminhos de investigação para além dos propostos por ele. A maior virtude dessa obra - e de seu pensamento - reside justamente na possibilidade de abrir diversas áreas de pesquisa que podem ser desbravadas a partir dos postulados e questionamentos nela colocados. Acreditamos que todo pesquisador que tenha contato com ela far-se-á questionamentos não apenas sobre, por exemplo, quais são as características do capitalismo contemporâneo (encontrando aliás múltiplos caminhos e respostas), nem apenas conhecerá melhor um conjunto de fenômenos contemporâneos que passa a encontrar sua explicação (por exemplo, o solidarismo ou a resignação) a partir do marco conceitual apresentado, mas também terá pistas sobre os objetos de pesquisa que lhe são próximos. Por exemplo, se estudarmos os processos ideológicos ou simbólicos, poderemos pensar em termos do que Scribano chama "religião neocolonial", ou se pesquisarmos as variantes de um novo espírito do capitalismo, poderemos lançar mão de conceitos como o de "dispositivos de regulação das sensações".

O livro está organizado em quatro capítulos ${ }^{1}$, somados à introdução, onde o autor expõe os contornos básicos sobre sua concepção da Economia Política da Moral, sobre o capitalismo neocolonial, sobre o papel do Estado na criação de uma sociedade de consumidores e sobre a as chamadas práticas intersticiais.

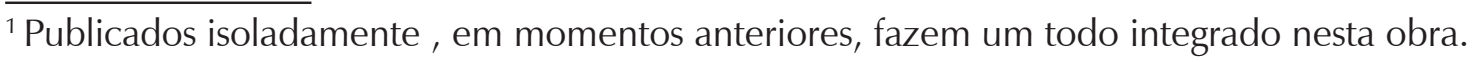


O primeiro capítulo trata do capitalismo como religião, sobre o capitalismo no momento atual, sobre o que denomina a "religião neocolonial" e sobre as práticas intersticiais. A partir do reconhecimento de que o tema da integração social é vigente ainda nas ciências sociais e da realidade da globalização, Scribano aborda a questão do capitalismo como religião, em que esta é assumida como um proceso permanente de elaboración de creencias encargadas de explicar el mundo y dar cuenta de las prácticas de los sujetos que lo construyen (p. 18), e em que o capitalismo é visto como generador de representaciones colectivas, con imágenes, articulaciones y creencias (p. 20). A seguir, explica-se a fase atual de expansão do capital, a qual se exerce com elementos de "depredação", de "regulação das sensações" e de "repressão". Há neste debate uma recuperação de teorias críticas do imperialismo, da dependência e do colonialismo. Contudo, talvez por questões de espaço, não fica esclarecido porque o conceito de "colonialismo" é ainda tão presente, quando as teorias imperialistas têm sido contestadas ou repensadas, justamente, desde teorias da globalização ou do Império (lanni, 2004; Hardt; Negri, 2001). Assumimos, a partir daí, que termos como colonial e neocolonial transitam por toda a obra, mas parecem referir mais a dispositivos de dominação do que à presença, por exemplo, de uma potência colonizadora, como se poderia encontrar nas teorias mais tradicionais do imperialismo.

Scribano define, então, três componentes da "tríade divina" da religião neocolonial: consumo mimético, solidarismo e resignação (p. 27). Estes funcionam como conceitos-chaves para explicar o capitalismo hoje, em que predominam, poderíamos dizer, comportamentos acríticos. A eles se contrapõem - talvez como uma forma de buscar esperança em um capitalismo desesperançador - as práticas intersticiais. Emerge, assim, uma nova tríade - que procura enxergar para além das práticas acríticas sinalizadas acima - composta pela "reciprocidade" e já não apenas pelo 
"consumo mimético"; o "gasto festivo" e já não somente um "solidarismo" que deixa intocadas as desigualdades; e a "confiança e credibilidade" em lugar da "resignação" (p. 32). Este capítulo primeiro mostra que o capitalismo se produz e reformula ininterruptamente, focado na expansão de sua capacidade de acumulação e na substancialização de realidades que aparecem como intransponíveis, mas mostra também que existem interstícios onde os indivíduos não se reduzem a repetir práticas acríticas²

No capítulo segundo, Scribano discorre sobre o que chama "a moral do desfrute". Torna-se central a conexão entre os conceitos de normalização, consumo e espetáculo. O autor argumenta que, no final do século XX, vários temas foram alvo de discussão, tais como a intimidade, as modernidades, as consequências da globalização; destacando como desafio repensar a noção de sociedade normalizada, tão presente nos anos 1960 e 1970. Relembrando as contribuições de Weber e os autores da Teoria Crítica, define a normalização, no início do século XXI, como composta de estabilização, repetição compulsiva, adequação nomológica e desconexão contextual. Sem se poder desenvolver o significado desses conceitos no espaço desta resenha, eles apontam a mostrar a evasão do conflito; a não autoreflexividade e perda de autonomia; a adaptabilidade; e a desconexão das relações sociais e de categorias de indivíduos tão presentes nos últimos séculos, como a do consumidor, cidadão, produtor, etc. A normalização hoje parece estar vinculada, então, a heteronomia, consenso, baixa reflexibilidade e dificuldades de agrupamentos sociais duradouros. Nesse contexto, o "desfrute" é um "desencaixe subjetivo", é um ya que adquiere sentido en su repetición

\footnotetext{
${ }^{2}$ Como um exemplo de desenvolvimentos empíricos que fundamentam as asserções teóricas - neste caso, sobre as práticas intersticiais - pode-se consultar a obra: "La fiesta y la vida. Estudios desde una sociología de las prácticas intersticiales", organizada por Adrián Scribano, Graciela Magallanaes e Maria Eugenia Boito (2012).
} 
indefinida (p. 47). O consumo, conclui Scribano, se torna crença, pois desfrutar é consumir. Desse modo: ...la constitución de las sociedades normalizadas en el disfrute inmediato son resultado y a la vez producen la intensificación del consumo como estrategia de la política económica en muchos de los estados del Sur Global (p. 50).

À normalização e ao consumo (mimético) precisa ser agregado o espetáculo. Scribano reconhece, em autores como Baudrillard, o valor conceitual dado ao espetáculo na explicação da estruturação das sociedades capitalistas. Mas, agora o espetáculo adquire uma nova conotação, pois forma, junto com a normalização e o consumo, uma tríade que explica a economia política da moral no capitalismo neocolonial. Nessa parte do livro, encontramos uma maior densidade conceitual, na qual se propõe uma leitura que integra autores como Baudrillard, Guy Debord e Marcuse. Nessa análise, o autor enfatiza el lugar central que tienen los espectáculos en la producción/reproducción de las políticas de las sensibilidades asociadas al disfrute inmediato que se actualiza en el consumo como eje reestructurador de la normalización de las sociedades (p. 51).

No terceiro capítulo, escrito em parceria com Angelica de Sena, mostra-se como as relações entre consumo mimético (agora como consumo compensatório), desfrute e capitalismo têm no Estado (a partir das políticas públicas) um de seus principais instrumentos de ação. Isso é observado nas políticas econômicas dos chamados "governos progressistas", em alguns países latino americanos, nos últimos 15 anos. Através de análises de discursos presidenciais nesses países, mostra-se a realidade complexa gerada pelas políticas levadas adiante por esses governos, que vai além da dicotomia maniqueísta entre mero assistencialismo ou inclusão social. O consumo compensatório (a partir das políticas de transferência, como é o caso do bolsa família no Brasil) é, em boa medida, um elaborador de sensibilidades, um regulador dos conflitos e um reparador das falhas que 
ocorrem entre Estado, mercado e sociedade civil (pp. 62-63). Os planos sociais, argumenta-se, têm como um de seus efectos más contundentes (..) mantener a los sujetos en los límites energéticos y nutritivos básicos, pelo qual constituyen una política de y sobre los cuerpos (p. 65).

Esses governos, identificados com perspectivas antiliberais, têm levado adiante políticas de inclusão da população no consumo; de ampliação do mercado interno; de fortificação da capacidade de demanda; de anexação do salário aos padrões - constantemente oscilantes - de consumo; e proposto este último enquanto medida de bem-estar social. O resultado de tudo isso tem sido a distorção e redução da linguagem e exercício da política a uma questão de consumo, enquanto mecanismo de elisão e evitação de conflitos.

Cabe questionar-se aqui, embora nesse capítulo não se faça tal aproximação conceitual, em que medida as políticas de inclusão no consumo levadas adiantes nesses países - apesar de uma postura discursiva antiliberal - não têm assumido um corte neoliberal? Foucault (2008) tinha ressaltado em suas investigações sobre a biopolítica, a dispersão de elementos constituintes de disposições neoliberais nas capilaridades imperceptíveis do tecido social por onde flui o poder, de um neoliberalismo como constituição ontológica e subjetiva da realidade social. Por sua vez, o Estado, enquanto detentor do monopólio legítimo de violência simbólica (Bourdieu, 2000), isto é, do poder nomotético de dizer o que as coisas são ou devem ser, encontrar-se-ia, nesse momento, alinhado a tais premissas.

Voltando à obra de referência, os contínuos esforços de aumento dos padrões de consumo enquanto critério de modernização, conectam, aliás, os indivíduos diretamente ao mercado financeiro. É no Estado que se faz possível a conexão entre elementos da sociedade bastante distantes - entre, por exemplo, o sistema financeiro e os setores pobres -, uma vez que cabe a ele o papel principal de provimento e gestão das estruturas 
de "sociabilidades e vivências". Desse modo, o Estado é um agente de primeira importância, através de créditos para el consumo, subsidios para el consumo, incentivos 'oficiales' para el consumo [que] se cruzan y superponen con el estado consolidado y en continuo desarrollo del capitalismo en su contradicción depredación/consumo (p. 67).

Nesse capítulo terceiro, é apresentado, para o caso argentino, um exemplo concreto que pode ser extrapolado para experiências de políticas públicas realizadas em outros países latino-americanos, mostrando a resignificação dos chamados programas de assistência social. O exemplo das mulheres do "conurbano bonaerense" que recebem "tarjetas" - auxílios para reinserção e participação social - é assimilável aos beneficiários do "Bolsa Família" e "Minha Casa Minha Vida" no Brasil. O "Bolsa Família" foi uma substituição do antigo programa social do "Fome Zero" que concedia uma ou duas cestas básicas a cada família beneficiária. A substituição da concessão do alimento pela quantia em dinheiro abriu pelo menos alguns pontos, que podem ser pensados a partir da referida obra: a) elucidar o papel do Estado enquanto agente partícipe de uma lógica mercantil, b) atribuir aos cidadãos um caráter de agentes consumidores, que devem atuar segundo a lei da melhor oferta, do custo-benefício, da especulação e da barganha, e, portanto, destituindo-os de seu potencial de contestação e participação política; e c) eximir o Estado de ponderar sobre sua responsabilidade no que diz respeito às condições dignas de vida social, do fornecimento dos recursos básicos, tal como escola, hospital e lazer.

Quinze anos passados, vão dizer Scribano e De Sena, no contexto de análise proposto, fazendo do consumo sua principal política de intervenção sobre o social, as consequências são óbvias: "têm-se gerado consumidores" (p. 81), isto é, poderíamos dizer, indivíduos que devem barganhar, especular proficuamente no mercado, aquilo que thes foi 
Sociologias, Porto Alegre, ano 18, no 43, set/dez 2016, p. 402-414

concedido pelos órgãos públicos, buscando sempre a maximização da existência social através do desfrute e gerando, em contrapartida, sensibilidades resignadas e desvinculadas dos processos de protesto social. Desse modo, poderíamos argumentar, o conceito de cidadania, outrora associado à participação social, é convertido à lógica de consumo.

Volta-se a trazer a questão do desfrute (e do desfrute imediato), não apenas na generalidade do capitalismo neocolonial, mas na sua conexão com as práticas estatais, através das experiências recentes latino-americanas. Afirma-se, então, que las prácticas de estatalidad se relacionan con las prácticas de una sociedad normalizada en el disfrute inmediato a través del consumo (p. 73).

Assim, do capítulo em análise, surge, em primeiro lugar, uma subjetividade autocentrada (observada nos resultados de aplicação de questionários à população argentina), isto é, o desfrute imediato é, cada vez mais, autocentrado no indivíduo consumidor, como objetivo que deve ser alcançado. Em segundo lugar, a expansão do consumo tem como papel chave evitar conflitos, colocar milhões de indivíduos no mercado e passar dos cidadãos aos consumidores. Em terceiro lugar, os planos sociais implicam também uma inserção dos indivíduos em sistemas de crédito, por meio dos quais os "pobres" aprendem a se movimentar no sistema financeiro (consumindo e endividando-se), e incluindo-se desse modo no mercado. Finalmente, temos como resultado "desfrute imediato", "consumo mimético", intervenção estatal através do "consumo compensatório" e, talvez, a consequência mais importante: o desalento aos protestos sociais.

O último capítulo é dedicado a mostrar que a sociedade capitalista do desfrute imediato é também uma sociedade de dejetos. Ao falar, especificamente, de América Latina, Scribano vê uma contradição, em que nem tudo é passividade e acriticismo. Se, de um lado, a cotidianidade é imersa em consumo mimético, solidarismo (que como vimos não 
muda as relações de desigualdade) e resignação; de outro, é nas práticas intersticiais que se encontram tramas del sentir questionadoras, baseadas no "gasto festivo", no "amor", na "esperança" e na "felicidade" (p. 93). Decerto, estas categorias não são prevalentes nas ciências sociais contemporâneas, sendo mais um desafio colocado pela perspectiva conceitual trazida por Scribano, na sua busca por experiências disruptivas.

Procura-se, no final da obra, entrelaçar as diferentes dimensões do social tratadas, agregando novas dimensões para explicar a caracterização do capitalismo no início do século XXI. A sociedade normalizada no "desfrute imediato" a partir do consumo, em uma economia política da moral que se baseia na "religião neocolonial", e na espetacularização do social tem como contrapartida a "depredação". Reafirma-se que vivemos em sociedades normalizadas en el disfrute imediato (p. 96), com incentivos e expansão do consumo, inclusive, desde as práticas estatais. Mas, adverte Scribano, aumento e diferenciação no consumo é também aumento e diferenciação nos dejetos. Por sua vez, o capitalismo não apenas produz dejetos, também produz "sacrifício", nova categoria para explicar seu funcionamento no início do século XXI. O sacrifício - contracara do desfrute - é a parte oculta do capitalismo neocolonial, exemplificado nos milhões de celulares usados no mundo - dentro da lógica do consumo e nas práticas dos espetáculos - que estão vinculados (ainda que de forma oculta) a processos de expropriação do mineral Lítio. Conclui Scribano: estamos diante de uma sociedade que retoma los desechos para usarlos como mercancías, una sociedad que sacrifica lo que está al margen, una sociedad que entrega en el altar de la producción una ofrenda cotidiana para que el mundo siga como está, una sociedad que ritualiza neo-colonialmente las energías corporales en pos de la depredación (p. 111). Assim termina esta obra, deixando no final um sabor amargo sobre os rumos do capitalismo, no início do século XXI. Ficamos com a impressão de estarmos dian- 
te de uma nova alienação, já não mais assinalada apenas pelo trabalho acumulado (oculto) na forma de capital, mas por uma ficção resultante dos investimentos estatais e de mercado em dispositivos de regulação das percepções, emoções e sensibilidades. O mundo enquanto paraíso na terra a ser desfrutado oculta sua contraface de depredação, deterioração, aumento das desigualdades e injustiças.

Em outras palavras, estamos diante de um diagnóstico que detecta, por trás do desfrute e do consumo, a cara oculta da produção de dejetos, de sacrifícios e de otredades que são colocadas à margem porque não acompanham a espetacularização do mundo de hoje. Contudo, a uma lógica expositiva que se depara no final com o "horror" do capitalismo, precisamos contrapor a "esperança" colocada pelo autor nas práticas intersticiais. Não se encontrará ali um sujeito universal "salvador da humanidade", mas, em contrapartida, se poderão vislumbrar sinais de vidas que procuram maior autonomia e desfrutes mais autodeterminados.

Voltamos, no final, a enfatizar a densidade conceitual deste livro de Scribano, como "síntese de múltiplas determinações". Predominam nesta obra manobras de linguagem, experimentações, e exigências gramaticais que talvez sejam resultado da própria complexidade da problemática que se busca investigar. Dito de outro modo, a densidade e complexidade conceituais - que se expressam também numa lógica da escrita na qual se observam alongamento de termos, tensionamento dos conceitos, multiplicação das categorias, diversas definições muitas vezes em tríades - tentam acompanhar a complexidade do capitalismo neocolonial - se aceitarmos esta definição - em boa medida explicado na sua natureza dissimulada, fugaz e esquiva à palavra que o persegue na tentativa de elucidá-lo.

Para finalizar, numa obra tão rica como a analisada aqui, corre-se o risco de valorizar o que é insignificante e de desvalorizar o que é medular. Esse foi o risco no qual incorremos ao abordar esta obra de Scribano. 
Seja como for, temos certeza de que trazemos para o leitor brasileiro uma perspectiva conceitual que, dentro da tradição crítica, o incitará a fazer novos questionamentos sobre o capitalismo no século XXI, sobre as práticas estatais, sobre o papel do consumo como imperativo moral contemporâneo, e sobre os objetos mais caros a seus interesses de estudo.

Pedro Robertt é Doutor em Sociologia pela Universidade Federal de Rio Grande do Sul, Professor e Pesquisador da Universidade Federal de Pelotas. $\triangle$ probertt21@gmail.com

Pedro Marchioro é mestrando em Sociologia na Universidade Federal de Pelotas. $\triangle$ pedro-marchioro@live.com

\section{Referências}

1. BOURDIEU, P. O poder simbólico. Rio de Janeiro: Bertrand Brasil, 2000.

2. FOUCAULT, M. Nascimento da Biopolítica. Curso no Collège de France (1978-1979). São Paulo: Martins Fontes, 2008.

3. HARDT, M.; NEGRI, A. Império. Rio de Janeiro: Record, 2001.

4. IANNI, O. A era do globalismo. Rio de Janeiro: Civilização brasileira, 2004.

5. SCRIBANO, A.; MAGALLANAES, G.; BOITO, M. E. (Orgs.) La fiesta y la vida. Estudios desde una sociología de las prácticas intersticiales. Buenos Aires: Ciccus, 2012.

6. SCRIBANO, A. Dísfrutalo! Una aproximación a la Economía Política de la Moral desde el consumo. Buenos Aires: Elaleph.com, 2015

Recebido: 08.01.2016

Aceite: 01.02.2016 